ÅRG. 6, NR. 2/3, 2017

ISSN (ONLINE) 2245-294X

Nanna Kann-Rasmussen, lektor, Institut for Informationsstudier, Københavns Universitet,

nanna.kann.rasmussen@hum.ku.dk

Gitte Balling, lektor, Institut for Informationsstudier, Københavns Universitet, gitte.balling@hum.ku.dk

\title{
Endelig!
}

\section{Historien om en tiltrængt public service succes}

\begin{abstract}
The article discusses why and how SKAM, as a public service production, has become a success. The article presents two interconnected challenges for public service broadcasters today. The first challenge pertains to the fact that young people in particular turn away from traditional television; the second challenge relates to the concept social media logic, a logic that is largely incompatible with public service logic. The article presents a discussion on how SKAM has met these challenges. The article focusses mainly on its Danish reception. Through SKAMs thematic emphasis, the series offers its intended audience (young people) a contemporary guide to Nordic values. Furthermore, its transmedial distribution has engaged a large audience of people who are otherwise moving away from traditional public service content.
\end{abstract}

Keywords: Public Service, SKAM, NRK, DR, Transmedialitet, Kulturpolitik

\section{Introduktion}

Traditionelt dansk public service-TV lider i disse år. Tallene taler deres tydelige sprog om en generation, hvis mediebrug i stigende grad går i retning af sociale medier og alternative underholdningsplatforme såsom YouTube.' Men tendensen ses ikke alene blandt unge. Blandt alle aldersgrupper, undtagen de ældste, er der en stigende tendens til at TV-forbruget foregår som streaming, enten via DR's streamingtjeneste eller gennem andre kommercielle aktører som HBO eller Netflix (Slots- og Kulturstyrelsen 2016, TV 2016). Kommercielle streamingtjenester er en udfordring, men også sociale medier udgør en udfordring for public service institutionerne. Med sociale medier kan man ikke alene se indhold andre har skabt, men man kan også selv skabe, dele, samarbejde og debattere. Unges brug af sociale medier udfordrer derfor traditionelle public service medier, fordi de ikke på samme måde rummer muligheden for aktiv deltagelse (Slots- og Kulturstyrelsen, 2016; Van Dijck \& Poell, 2015; Edmond, 2014). Den digitale revolution har således skabt en situation, hvor nye aktører på medieområdet tilbyder både indhold og platforme til indholdsskabelse uafhængigt af hvor og hvornår behovet opstår.

Så meget desto større er forundringen over den succes, som den norske public serviceproducerede ungdomsserie SKAM i 2016 har opnået i hele Norden. SKAM har ikke alene ramt den erklærede målgruppe, de unge, for også blandt voksne har serien skabt mange dedikerede fans. DR må med længsel se mod den norske søsterorganisation NRK, som tilsyneladende er lykkedes med at få unge til at interessere sig for public service 
TV. Spørgsmålet, som denne artikel søger at besvare, er: Hvorfor og hvordan lykkedes SKAM - set i et public service perspektiv?

I det følgende præsenteres to sammenhængende udfordringer for public serviceinstitutioner i dag. Herefter diskuteres hvordan SKAM overvinder udfordringerne dels gennem hvad der fortælles og hvordan der fortælles. Artiklen er skrevet ud fra et dansk perspektiv, og har således primært eksempler fra den danske reception af serien.

\section{Udfordringer for public service}

Public serviceinstitutionerne er tæt forbundet med etableringen af det moderne demokratiske velfærdssamfund, som det etableredes i de nordiske lande i sidste halvdel af det 20. århundrede (Mouritsen, 2006, Larsen, 2014a). Begrebet public service lader sig kun vanskeligt definere entydigt, men rummer flere forskellige betydninger, ligesom begrebet løbende har formet sig efter den samfundsmæssige og mediemæssige udvikling (Syvertsen, 2003). Der hersker dog enighed om, at public service indhold er ikke-kommercielt, og har til opgave at understøtte befolkningens kulturelle og demokratiske dannelse med henblik på en styrkelse af demokratiet. Public service skal endvidere formidle og styrke det nationale sprog og den nationale kultur. Ligeledes er nøgleord som kvalitet, uafhængighed og bredde centrale (Syvertsen, 2003; Mouritsen, 2006; Larsen, 2014b). Public service institutioners rolle kan således ses som underst $\varnothing t t e n d e$ for det repræsentative demokrati, der klæder borgerne på i forhold til at deltage i den offentlige debat og forholde sig til aktuelle problemstillinger på såvel samfunds- og individniveau. I Danmark har rollen som opdrager stået stærk i DR's selvbevidsthed frem til monopolbruddet i 1980'erne. Med den øgede konkurrence fra både danske og udenlandske kommercielle aktører er public service begrebet blevet udvidet i retning af en bredere, mere efterspørgselsorienteret betydning (Mouritsen, 2006). Udviklingen i retning af globalisering og digitalisering har dog ikke betydet en bevægelse væk fra de oprindelige målsætninger, men et delvist opg ør med den mere formynderiske og alvidende rolle som de nationale public service stationer oprindeligt indtog.

Som mange andre kulturpolitiske områder er public serviceinstitutionerne udfordrede i disse år. I det følgende vil vi pege på to sammenhængende udfordringer for public service TV.

Den første udfordring knytter an til public serviceinstitutionernes legitimitet. Da public service institutionerne i sin tid blev oprettet, var et af de stærkeste bagvedliggende argumenter, at der ikke var noget alternativt tilbud, "the scarcity argument" (Larsen, 2014b, s. 65). Der var simpelthen mangel på fx neutrale nyheder, radiokoncerter og debatprogrammer. Både Syvertsen (2003) og Van Dijck \& Poell (2015) peger på, at eksistensen af et privilegeret offentligt rum (altså at public serviceinstitutionerne tidligere "havde kanalen for sig selv") er blevet udfordret, i første omgang af kommercielle udbydere og siden af de sociale netværksmedier. I en tid hvor public servicestationer som DR var den eneste udbyder af indhold, var indholdet i sig selv værdifuldt, simpelthen fordi det var det eneste, der var. I dag er mange centrale diskussioner om fx politik, samfund og kultur flyttet fra public serviceinstitutionernes sendeflader til sociale medier, hvilket undergraver knaphedsargumentet. Det betyder, at den yngre del af befolkningen vender sig væk fra TV-mediet. Som beskrevet i indledningen er det tydeligt, i hvert fald i Danmark, at DR, som er den suverænt største udbyder af public service indhold, ikke har godt nok fat i de unge. De unge er fremtidens mediebrugere og derfor vil en manglende interesse fra de unges side på længere sigt undergrave DR's legitimitet. Public serviceproduceret TV er ikke bare indhold skabt inden for en særlig national ramme, men er også indhold skabt med et særligt formål og en særlig forpligtelse. Public service medier er sat $\mathrm{i}$ verden for at producere og tilgængeliggøre ikke-kommercielt indhold som 1) lever op til bestemte kvalitetsnormer, 2) som tilgodeser både en bredde og mere nicheprægede behov, 3) som underst $\varnothing$ tter national kultur og sprog samt 4) virker for en styrkelse af demokratiet (Mouritsen, 2006). Når seerne vender ryggen til public service-TV, udgør det i første omgang et kulturpolitisk problem, mens det på længere sigt kan risikere at skabe en samfundsmæssigt og demokratisk problem.

Den anden udfordring vi vil fremdrage, udgøres af de sociale mediers logik. Denne udfordring er beskrevet af Van Dijck og Poell $(2013,2015)$. Logikbegrebet referer til de processer, principper og praksisser gennem hvilke de sociale medier behandler information, nyheder og kommunikation samt hvordan social interaktion gøres muligt. 
Van Dijck og Poell (2013) peger på 4 logikker, der er kendetegnende for sociale medier. Programmability, dvs. muligheden for både medieplatformen og brugerne for at styre og programlægge flow af indhold. Popularity, muligheden for på samme tid at måle emners og personers popularitet og gennem algoritmer at manipulere disse rankeringer. Connectivity, muligheden for at forbinde brugere med indhold og annoncører. Begrebet henfører til hvordan den givne platform i samspil med brugeren ikke blot muliggør forbindelser mellem brugere men i mange tilfælde pusher bestemte forbindelser gennem forslag, adgang til potentielle nye kontaktpersoner, annoncører o.l. Datafication, anvendelse af data og algoritmer til at måle, forudsige, men også forme brugeres adfærd, holdninger og præferencer. Et vigtigt aspekt af datafication er, at disse målinger er usynlige for os som brugere. I dag er det evident, at de sociale medier er store forretningsimperier, hvor vi som brugere underlægger os kommercielle aktørers regler og mere eller mindre frivilligt betaler med vores private data, et vilkår som den kritiske teoretiker Christian Fuchs (2013) med et marxistisk perspektiv har kaldt udnyttelse af arbejdskraft. De sociale mediers logik udgør en udfordring for public service af flere grunde. Public service indhold er traditionelt udbudt gennem massemediernes en-til-mange distribution. I dag betyder de sociale mediers programmability og connectivity, at vi er blevet vant til selv at kunne deltage (gennem fx kommentarer, likes og diskussionstråde) og kommunikere med andre. Det betyder, at TV og radio kan fremstå som kedelige og uattraktive (en uvidenskabelig men tankevækkende artikel om hvordan TV og radio opleves af unge er Alfort, 2017). Ligeledes har public service indhold skullet være opbyggeligt og "for alle", hvilket betyder, at det kvalitetsbegreb, der har været fremherskende for public service, er anderledes end på de sociale medier, hvor kvalitet måles i antallet af likes og clicks.

Van Dijck og Poell (2015) diskuterer hvordan sociale netværksmedier i de tidlige stadier promoverede sig selv som en neutral infrastruktur, hvor alle kunne fylde indhold i. Den udvidelse af den offentlige sfære, som digitale sociale medier kan ses som, er altså ikke et neutralt offentlig rum på samme måde som public service stationerne var tænkt. Til gengæld tilbyder de sociale medier, med deres specielle logikker, en anden form for interaktion fx gennem distribution via personlige anbefalinger og ikke mindst muligheden for selv at deltage ved at producere og dele indhold. Et forhold som særlig Henry Jenkins $(2006,2008)$ har beskæftiget sig med. Han beskriver de frigørende potentialer som de sociale medier rummer, gennem begrebet konvergens- og deltagerkultur, der beskriver internettets muligheder for nye fællesskaber og kunstnerisk udfoldelse, bl.a. gennem sænkede barrierer for at komme til orde. De sociale medier udgør således en form for offentligt rum, hvor det private og det offentlige er vævet sammen, og hvor almindelige mennesker har større mulighed for at initiere debat end tilfældet er ved traditionelle massemedier (se fx Rønlev, 2014). De sociale medier bærer på den ene side løftet om en offentlig sfære, hvor alle kan komme til orde, på den anden side er prisen for at deltage $\mathrm{i}$ den offentlige debat, at man deltager i et gennemkommercialiseret rum, hvor prisen er private data.

Public serviceinstitutionerne kæmper med disse udfordringer overalt i vesten. I det følgende skal vi derfor dykke ned i den opløftende historie om en tiltrængt succes.

\section{SKAM: en kulturpolitisk succes}

Med SKAM har NRK skabt en public servicesucces, som vi mener kan forklares gennem kombinationen af hvad der fortælles, og hvordan det fortælles.

\section{Hvad: SKAMs tematikker og debatskabelse}

Som nævnt ovenfor, er det en kerneopgave for et public servicemedie at understøtte befolkningens kulturelle og demokratiske dannelse med henblik på en styrkelse af demokrati og sammenhængskraft i samfundet. I det følgende vil vi, gennem to eksempler og en kort diskussion, vise hvordan SKAM løser denne opgave.

Sæson 3 udspiller sig som en kærlighedshistorie mellem Isak og Even. Som seere følger vi Isaks kvaler med at erkende over for sig selv og senere sine venner, at han er forelsket i Even. På et tidspunkt slipper det ud, og Isak skal fortælle sine venner at han har en greie med Even. I scenen føler vi Isaks nervøsitet, der er meget på spil, men scene forløses, da to af vennerne Mahdi og Magnus nærmest glemmer, at det er Isak det handler om, fordi de kommer til at diskutere hvad forskellen egentlig er mellem at være panfil og bifil. Denne diskussion fortsatte både på sociale medier (eksempelvis kosegruppa.dk på Facebook) og i etablerede medier (en søgning i artikelbasen Infomedia på ordene Isak, homoseksualitet og skam gav 56 artikler fra juni 2016 -juni 2017). 
Ligeledes har Nooras og Vildes vekslende grader af anoreksi, der tages op i sæson 2, fostret flere debatter om spiseforstyrrelser og forventningspres hos unge. Begge piger holder op med at spise, når livet er svært, men de hjælper hinanden ved at lave tortilla. Udtrykket "kroppen din trenger potet" er blevet et af de norske udtryk, der sammen med føkkboy og serr er kommet ind i det danske sprog, men det er samtidig et udtryk, som husker os på, at vores krop faktisk har godt af at få rigtig mad og ikke kun den "tyggis og cola light", som på et tidspunkt udgør Vildes morgenmad.

Ovenstående er blot eksempler på samfundsrelevante tematikker som SKAM tager op, og lykkes med at sætte til debat, også i en bredere offentlighed end blot seriens målgruppe.

Udover at danne baggrund for en offentlig debat, leverer SKAMs tematikker en moderne nordisk referenceramme til sin målgruppe. Serien tilbyder sine unge seere nogle ganske bestemte løsninger på, hvordan man kan forholde sig til vanskelige problemer, og viser at det er gennem kommunikation og fællesskab, at man overkommer sin skam. SKAM slår konsekvent til lyd for moderne nordiske værdier som tolerance, inklusion, og åbenhed, og mangfoldighed. Værdier som i øvrigt ligger i tråd med kulturministeriets seneste kanon, nemlig Danmarkskanonen, hvis formål det er at synliggøre og promovere netop det nordiske værdisæt (eksempler på disse værdier er frisind, kønsligestilling og tillid).

\section{Hvordan: SKAM tilbyder deltagelse og tiltrækker seere gennem moderne distributionsformer}

At serien kan tjene som referenceramme for en generation, der sædvanligvis henter sine identitetsmarkører i en bredere vestlig kontekst, handler ligeledes om måden serien fortælles på og de medier, der inddrages $i$ fortællingen. SKAMs distributionsform er banebrydende, fordi den blander en massemedielogik med en netværkslogik. Ifølge Hjarvard (2015) er massemediernes logik karakteriseret ved en professionel og omkostningstung indholdsproduktion, hvor indhold udvælges centralt og formidles til et anonymt publikum ud fra viden om bestemte segmenter. Produktionen af SKAM er professionel og indholdet er valgt efter nøje analyser af målgruppens karakteristika. På denne måde er der en klar skillelinje mellem seriens producenter og deres modtagere, i modsætning til fx indhold som produceres og remixes af amatører på YouTube.

Samtidig udnytter SKAM dele af de sociale mediers logikker til at understøtte sin egen fortælling og skabe fascination hos seerne. SKAM er produceret som traditionelt flow TV, men distribueres i realtime og i mindre klip igennem ugen, så man som seer ikke ved, hvornår næste bid kommer. Den primære distribution foregår på nettet på distributionsplatformen http://SKAM.p3.no som tilgås alene for at opleve SKAM. Indholdet i serien begrænser sig ikke kun til filmklip, men også Instagramopslag og screenshots af SMS eller Messenger meldinger. De første udsendes simultant på hjemmesiden og på karakterernes Instagramprofiler, som man også kan følge. Det betyder, at seerne opdateres gennem deres feeds på sociale medier og at serien følges efter samme logik, som man følger sine venskaber eller andre platforme, man abonnerer på. Ugens små klip samles efterfølgende af NRK og sendes hver fredag som en del af den faste sendeflade, en distributionsform, som for de indviede minder om genudsendelse.

En vigtig pointe er, at hvert indholdselement på http://SKAM.p3.no følges af et kommentarfelt og en mulighed for at like klippet, Instagramopslaget eller meldingen. Kommentartråden modereres af NRK, og derfor er den altid ryddelig, kronologisk, og tonen er sober. På denne måde giver NRK adgang til en offentlighed, hvor SKAM og relaterede emner kan diskuteres i den form, som vi er vant til (sociale medier), men uden at vi skal betale med vores personlige data, modtage reklamer eller på anden måde underlægge os de dele af sociale mediers karakteristika, som er uforenelige med public service. Dog skal det siges, at den største del af diskussionen forgår på platforme udenfor NRK, fx på Facebook og tumblr. Her må diskussionen og brugerne underlægge sig de medielogikker som Van Dijck og Poell (2013) beskriver.

\section{Afsluttende diskussion}

Som vi har vist er SKAM en bemærkelsesværdig public servicesucces, idet serien har overvundet mange af de udfordringer, som de nordiske public service institutioner kæmper med. For det første har SKAM overvundet nogle af de udfordringer, som de sociale medier udgør for institutioner som DR og NRK, ikke ved at konkurrere 
mod dem eller ved at udelukke dem, men ved at integrere dem både i fortællingen og i formidlingen af den. SKAM har så at sige løst den gordiske knude ved, for det første, at bruge de sociale medier som en vigtig del af narrativet og som en naturlig del af hovedpersonernes liv, og for det andet ved samtidig at skabe sin egen ikkekommercielle platform som hjemsted for serien. skam.p3.no er således både det sted, man kan se de små klip først og et sted fans kan diskutere og like forskellige dele som indgår i serien. Alt dette foregår på et sted, der importerer funktionaliteter og logikker fra sociale medier, men som samtidig fritager brugerne fra at skulle betale med deres private data, fordi platformen er en del af public service koncernen NRK og fordi man ikke skal logge ind.

Ligeledes har SKAM fostret den deltageraktivitet, som både ud fra et kulturpolitisk og fortællemæssigt perspektiv er et vigtigt mål for værdien, på flere planer. At TV-serier har en engageret og aktiv fanbase er dog ikke noget nyt (Matt Hills, 2002; Jenkins, 2006; Ryan \& Thon, 2014; Kampmann Walther, 2012). Specielt har de nye TVserier, fx Game of Thrones ligesom store transmediale fortællinger såsom Star Wars og Harry Potter, en stor international fanskare, der debatterer, teoretiserer og analyserer både tematisk indhold, helte, skurke og skuespillere. Disse fortællinger spiller på vores ludiske begær (Kampmann Walther, 2012). At være seer/fan er ikke kun at lade sig underholde eller være forelsket i seriens univers eller personer, men er også gådeløsning på et højt plan, hvor man sammen med andre fans udforsker den fiktive verden, og leder efter de underlæggende logikker, der binder begivenhederne sammen.

Når det gælder store kommercielle produktioner, er det værd at bemærke, at formålet med at skabe en transmedial fortælling er at skabe et univers som potentielt kan blive ved at udgøre kilden til film, afsnit, spil etc. Der ligger således et økonomisk incitament bag etableringen af en verden, som fans kan dyrke (Mittel, 2014). Formålet med SKAM og den måde som serien fortælles og distribueres på er derimod at skabe et univers, som de unge for det første kan spejle sig i og identificere sig med, og som kan inspirere til at debattere temaer som optager både unge og voksne. SKAM skaber et offentligt rum hvor de unge kan mødes og debattere, hvor de kan finde inspiration til at tackle deres egne problemer og hvor de kan se hvordan man hjælper andre med deres. Seriens tematiske fokus på kommunikation, tolerance og mangfoldighed reproduceres i den transmediale distribution og i de fanfællesskaber serien har medført. SKAM forener således det bedste af begge verdner. En public service succes.

\section{Referencer}

Alfort, S. (2017). Erik på 15 år har aldrig rigtigt set fjernsyn. Mød fremtidens mediebrugere. Zetland. 27 juli 2017.

DR Medieforskning (2017). Medieudviklingen 2016. Lokaliseret på http://www.dr.dk/NR/rdonlyres/EDBEE3F45C3E-439E-A08E-870734C3CD72/6150035/medieudviklingen 2016.pdf

Edmond, M. (2014). All platforms considered: Contemporary radio and transmedia engagement, New Media and Society 17(9), 1-17.

Fuchs, C. (2013). Social media and capitalism. I T. Olsson (Red.), Producing the Internet. Critical perspectives of social media, (pp. 25-44). Göteborg: Nordicom.

Hills, M. (2002). Fan Cultures. London: Routledge.

Hvenegaard Rasmussen, C. (2015). Brugerinddragelse og kulturpolitisk kvalitet. Nordisk Kulturpolitisk Tidsskrift, 18(1), 81-100.

Jenkins, H. \& Bertozzi, V. (2008). Artistic expression in the age of participatory culture. I S. J. Tepper \& B. Ivey (Eds.), Engaging art. The next great transformation of America's cultural life (pp. 171-195). New York, NY: Routledge.

Jenkins, H. (2006). Convergence culture. New York: NYU Press. 
Kampmann Walter, B. (2012). Computerspil og de nye mediefortællinger. Frederiksberg: Samfundslitteratur.

Klastrup, L. \& Tosca, S. (2014). Game of Thrones: transmedial Worlds, fandom and social gaming. I M.L. Ryan \& J.N. Thon (Eds.), Storyworlds across media: towards a media-conscious narratology. (pp. 295-314). Lincoln \& London: University of Nebraska Press.

Mouritsen, P. (2006). I folkets tjeneste: Public service som omstridt begreb. Journalistika (3), 65-85.

Kongelege Kulturdepartement (2014). Stortingsmelding 38. Open og Opplyst. Lokaliseret på https://www.regjeringen.no/contentassets/98dcafb6544e4161b32b5c2e8b978d20/nnno/pdfs/stm201420150038000dddpdfs.pdf

Kulturministeriet (2014). Mediepolitisk aftale for 2015-2018. Lokaliseret på http://kum.dk/fileadmin/KUM/Documents/Kulturpolitik/medier/Medieaftalen/Medieaftale 2014/Medieaftale af 26 juni 2014endelig1.pdf

Kulturstyrelsen (2014). DRs public service kontrakt for 2015-2018. Lokaliseret på http://www.kulturstyrelsen.dk/fileadmin/user upload/dokumenter/KS/medier/tv/DR/Kontrakter/Kontrakt 20 15-2018/DRs_PS-kontrakt_2015-2018.pdf

Larsen, H. (2014a). Legitimation work in state cultural organizations: the case of Norway. International Journal of Cultural Policy, 20(4), 456-470.

Larsen, H. (2014b). The legitimacy of public service broadcasting in the $21^{\text {st }}$ century: the case of Scandinavia. Nordicom Review, 2, 65-76.

Mittel, J. (2014). Strategies of storytelling on transmedia television. I M.L. Ryan \& J.N. Thon (Eds.), Storyworlds across media: towards a media-conscious narratology. (pp. 253-277). Lincoln \& London: University of Nebraska Press.

Mouritsen, P. (2006). I folkets tjeneste: Public service som omstridt begreb. Journalistika, 3, 65-85, http://ojs.statsbiblioteket.dk/index.php/iournalistica/article/view/1797/1619

NRK (2016). Langtidsstrategi 2016-2021 lokaliseret på https://fido.nrk.no/ac747416b8a31f633cc2fe88edc653a07d0a842797f0b644b4bbdb208999770f/nrk strategi 2016 20121.pdf

Rønlev, R. (2014). Danske netaviser som webmedier for retorisk medborgerskab. Ph.d. afhandling, København: Københavns Universitet.

Slots- og Kulturstyrelsen (2016). Mediernes udvikling i Danmark: TV. Lokaliseret på http://slks.dk/fileadmin/user upload/dokumenter/medier/Mediernes udvikling/2016/TV/TV 2016 FINAL TIL UPLOAD.pdf

Syvertsen, T. (1999). The many uses of the "Public Service" concept. Nordicom Review, 20(1), 5-12.

Syvertsen, T. (2003). Challenges to public television in the era of convergence and commercialization. Television \& New Media 4(2), 155-75.

van Dijck, J. \& Poell, T. (2013). Understanding social media logic. Media and communication, 1(1), 2-14.

van Dijck, J. \& Poell, T. (2015). Making public television social? Public service broadcasting and the challenges of social media. Television \& New Media, 16(2), 148-164. 


\begin{abstract}
'I den seneste udgave af Mediernes udvikling i Danmark (Slots- og Kulturstyrelsen 2016) er 12-18-åriges daglig sening af traditionelt tv faldet med 52,2 \% siden 2010 (figur 12). Unge mellem 16-34 år er til gengæld blandt de mest ivrige brugere af streaming (30 \% dagligt) (figur 27). I DR's egen årlige undersøgelse Medieudviklingen viser resultatet af spørgsmålet Hvad benyttede du i går? at $80 \%$ af 15-29årige så korte videoer og klip på nettet mod 52\%, der så traditionelt tv (DR, 2017s. 27).
\end{abstract}

